\title{
A Comparative Analysis of Condom Use Among Unmarried Youths in Rural Community in Nigeria
}

\author{
A. F. Fagbamigbe ${ }^{1, *}$, A. S. Adebowale ${ }^{1}$, F. A. Olaniyan ${ }^{2}$ \\ ${ }^{1}$ Medical Statistics and Environmental health, Faculty of Public Health, College of Medicine, University of Ibadan, Ibadan, Nigeria \\ ${ }^{2}$ Staff Medical Service Department, University College hospital, Ibadan, Nigeria
}

\begin{abstract}
Globally, youths are more sexually active than any subgroup of the population. In Nigeria, the prevalence of condom use among youths is low. This study explored and compared condom use among in-school youths and out-of-school youths in south western Nigeria. This population based study used multistage random sampling technique to select eligible 600 youths aged 15-24 years which included 300 high school students and 300 out-of-school youths in Ekiti West Local Government area of Ekiti state, Nigeria. Descriptive statistics, t-test, chi square test and logistic regression were used for analysis. The mean age of in-school youths and out of school youths were $18.1 \pm 2.2$ years and 19.0 \pm 2.7 years respectively. Overall, $35.5 \%$ of all sexually active respondents, $29.8 \%$ in-school and $40.8 \%$ out-of-school youths reported to have ever used condom during sexual intercourse $(p<0.05)$. Regular condom use was recorded among $10.7 \%$ in-school youths or their partners and $20.6 \%$ among the out-of-school youths. Out-of-school youths are about one and half times more likely to use condom than in-school youths, $(\mathrm{p}<0.05)$. The study concluded that although, condom use is low across the study population, but higher among out-of-school youths. Youths aged 15-24 should be given free access to condom particularly the in-school youths.
\end{abstract}

Keywords Condom Use, HIV/AIDS, In-School, Out-of-School, Nigeria

\section{Introduction}

Globally, youths are more sexually active than any subgroup of the population. In Nigeria, the prevalence of condom use among youths is low[1]. As part of the arsenal to combat HIV/AIDS aimed at achieving theme 6 of the Millennium Development Goal (MDG), studies on condom use will certainly be of interest to policy makers. Although various studies have investigated condom use among youths in Nigeria, only very few have compared condom use among in-school and out-of-school youths

Sub-Saharan Africa still bears an inordinate share of the global HIV burden. Although the rate of new HIV infections has decreased, the total number of people living with HIV continues to rise. In 2009, that number reached 22.5 million in Africa, $68 \%$ of the global total[3] with over 2.8 million new infections in 2006. Ten million young Africans between the ages of 15 and 24 and 3 million children are infected[2]. According to UNAIDS, $61 \%$ of HIV-infected people in sub-Saharan Africa are female and the gap is increasing. The differences in infection levels are most pronounced among young people (aged $15-24$ years) with, on average, 36

* Corresponding author:

franste174@yahoo.com (A. F. Fagbamigbe)

Published online at http://journal.sapub.org/phr

Copyright (C) 2011 Scientific \& Academic Publishing. All Rights Reserved young women living with HIV for every 10 young men in sub-Saharan Africa[2]. The estimated 1.3 million people who died of HIV related illnesses in sub-Saharan Africa in 2009 comprised $72 \%$ of the global total of 1.8 million deaths attributable to the epidemic. HIV/AIDS is now the leading cause of death in Africa and the fourth largest cause of death globally[3]

Preventing the spread of HIV infection among youths aged $15-24$ years is critical to reducing the incidence of new HIV infection. This is because young people make up a substantial part of the population and first sexual intercourse commonly occurs during this age group. HIV prevention could be achieved by the use of a condom. A study of clinic attendees in Ibadan, Nigeria showed that the peak prevalence (65\%) of HIV infection was among those aged 21-30 years, most of who were probably infected during adolescence[4]. Nigerian youths are also vulnerable to the complications associated with unprotected sex, including other sexually acquired infections, unsafe abortion, and subsequent infertility or death[5]

The World Health Organization estimated that one out of every twenty adolescents contact sexually transmitted diseases (STD) each year. Furthermore, adolescents and young adults account for a disproportionate share of the increase in reported cases of syphilis and gonorrhea worldwide[3]. The Association for Reproductive and Family Health [6] found that $35.5 \%$ of students reported cases of sexually transmitted infections in a baseline survey of 
secondary school students in Oyo state.

One in every five person in the world is an adolescent[3]. Both in-school and out-of-school youths constitute a sizeable proportion of the Nigerian population. The 15-to-19 year age group accounts for approximately one fourth of Nigeria's population and forms about 26 percent of the population of Ekiti state[7]. It is necessary to put into perspective the sexual behaviour of youths because it is central to the prevention of transmission of HIV and other sexually transmitted infections. There is need to assess the effect of intervention programmes that have hitherto been put in place to address the sexual behaviour among youths as far as condom use in sexual intercourse is concerned.

Although most previous studies on adolescent sexuality have focused on in-school youths alone but most of the secondary school age youths in Nigeria are not in school (63\% boys and $79 \%$ of girls)[7]. This study aims to investigate sexual risk behaviour amongst Nigerian youths, particularly focusing on condom use in comparison between in-school and out-of-school youths in order to inform local/regional/ national for reproductive health education and policy planning. The study population consists of in-school and out-of-school youths aged 12-24 years in Ekiti state of Nigeria.

The youths as a group are generally thought to be healthy because they have survived the diseases of early childhood and are decades away from the conditions associated with old age[3], yet many of them die prematurely. The transitional period from childhood to adolescence is characterized by an increase in personal control, responsibility and independence. During this period, they explore and develop their sexuality, gender and sex roles[8]. Responses to societal sexual norms and expectations in this context can be seen as one of the key tasks of the youth. Traditional norms in most Nigerian cultures demand premarital sexual abstinence until entry into marital unions. Nevertheless, the norms have almost disappeared in all ethnic groups[9].

Premarital sexual activity among young people is increasing in many regions of the world. The reported male and female sexual intercourse prevalence is $82.4 \%$ respectively among young secondary school girls in Nairobi, Kenya[10]. Similarly, among Kenyan students surveyed in the late 1980s, 48 percent of males in primary school and $69 \%$ of males in secondary school were engaged in sexual activities, compared with $17 \%$ and $27 \%$ of girls in primary and secondary schools respectively[11]. The studies documented that more males than females reported early sexual encounters. In Ivory Coast, the reported prevalence of sexual activity is $23.8 \%$ among female adolescent students surveyed[12].Very dangerous health risks of early sexual activity are connected with the non-use of condom. Sex with multiple partners is a risky sexual behaviour common among adolescents[13] and is as risky as avoidance of condom. The result is that Nigerian adolescents are at high risk of the undesirable outcomes of sexual activities including unintentional pregnancy, sexually transmitted diseases such as gonorrhoea, syphilis and HIV. They are also vulnerable to the complications associated with these conditions, including unsafe abortion, infertility or death[5].

Literatures had held divergent opinion on the attitudinal use of condom among adolescents[14, 15, 16, 17]. However, differences existed within subgroup of youths in patterns of condom use. Condom is useful for the prevention of sexually transmitted diseases, rather than just for HIV. This was well discussed in[18, 19, 20].

It is therefore important to review the trend in risky sexual behaviours among Nigerian youths especially in Ekiti area where similar studies are very rare. This study aims to investigate sexual risk behaviour amongst Nigerian young population, particularly focusing on condom use in comparison between in-school youths and out-of-school youths so as to inform local, regional, national and international government and non-governmental agencies for health education, health promotion and health intervention purposes. This is with the view of providing information to inform policy on the reproductive health needs of Nigerian youths.

\section{Materials and Methods}

This study was carried out in Ekiti West Local government area, Ekiti-State, south western Nigeria. It is a rural setting and the inhabitants are predominantly Yoruba. About $70 \%$ of the people engage in farming. It was a population based cross-sectional study. The target populations were unmarried youths aged 15 to 24 years. Students and youths who dropped out of school and are now learning trade or apprentice represent the in-school and out-school population respectively. A multistage probability sampling, whereby six political wards were randomly selected out of the total of 13 wards in the community, one school each was later randomly selected from each of the six chosen wards and a proportional number of in-school youths were randomly selected from each school to produce 300 in-school youths aged 15-24 years across the local government area. Out-of-school workshops and other locations were enumerated using Enumeration Area as designed by National Population Commission in the preparation for 2006 census exercise. All eligible out-of-school youths in a chosen Enumeration area were purposely interviewed until a proportion allotted for the Enumeration area is filled up. In all, total of 300 respondents were selected for out-of-school respondents. A total sample size rounded up to 600 youths consisting of 300 in-school and 300 out-of-school youths were used for the study.

The research tool used for the data collection was a pre-tested questionnaire which contained socio-demographic information relevant for the study. The people in the area understood Yoruba better than English language. Therefore, to ensure a good understanding of the questions in the questionnaire, a Yoruba version was created. Interviewers who could speak English and Yoruba fluently were recruited and properly trained for data collection exercise. Mock 
interviews were conducted at the study location before the actual survey. The respondents were all literate, so the interview tool was anonymous self-completion questionnaire. The informed consent was obtained from each of the participants in the study before conducting the interview. Trained interviewers explained each question in the questionnaire to the randomly selected respondents before the respondents gave anonymous responses. This approach has helped in obtaining correct and valid answers through avoidance of observer and informant bias.

The authors who doubled as the supervisors reviewed the administered questionnaires daily to ensure internal consistency and accuracy. Descriptive statistics was carried out on the data to capture frequency distribution and necessary measures of locations and variations. Chi-square was used to test the association between variables of interest. The multivariate analysis was performed using Stepwise logistic regression. The cut-off for variable inclusion was a $\mathrm{p}$-value of 0.1 while all $\mathrm{p}$-values less than 0.05 were considered statistically significant.

One limitation observed in this study was we did not collect any data about condom use for different types of sex (penile-vaginal, oral and anal).

\section{Results}

A total of 600 youths were interviewed. 300 were in-school youths and 300 were out-of-school youths. As shown in Table 1, the ages of the respondents ranges from 15 to 24 years with a mean of $18.6 \pm 2.5$ years. The in-school youths were significantly younger than the out-of-school youths $(p=0.000)$. The overall mean age of sexual initiation was $13.4 \pm 1.4$ years, with the out-of-school youths initiating sex at a significant older age $13.6 \pm 1.2$ vs $13.2 \pm 1.5$ years, $(p=0.002)$. Sixty five percent of the in-school youths were males compared with $69.3 \%$ of out-of-school youths. Only $30.7 \%$ of out-of-school youths were females $(\mathrm{p}=0.297)$. The range of age at first sexual intercourse was 11-17 for both groups. Also, about half of the in-school youths and out-of-school youths were Christians $45 \%$ were Muslims and only $4 \%$ were traditional worshippers. Over $76.3 \%$ of the in-school youths were teenagers while $60.7 \%$ of out-of-school youths were teenagers $(\mathrm{p}=0.000)$.

\subsection{Sexual behaviors of respondents}

In Table 2, a total of 377 respondents out of which 181 $(60.3 \%)$ were in-school youths and 196 (65.3\%) were out-of-school youths had had sexual intercourse as at the time of the survey. This difference was however not significant $\left(x^{2}=1.606, p=0.237\right)$. Similar pattern of proportions $(63.3 \%$ and $61.9 \%)$ of males and females of all respondents had ever had sex $(\mathrm{p}=0.408)$. Within group comparisons showed that the proportions were relatively close from $59.0 \%$ among the female in-school youths to $61.0 \%$ among the male in-school youths $(\mathrm{p}=0.805)$; and from
$65.2 \%$ among the female out-of-school youths to $65.4 \%$ among the male out-of-school youths ( $p=0.999)$. In terms of age, respondents who had ever had sex were found to be highest in age group 21-24 years. Generally, the proportion of youth who had ever had sex was found to increase with increasing age (Table 2). This was $42.4 \%$ among the $15-17$ years-olds, $67.4 \%$ among the $18-20$ years-old and $88.3 \%$ among the 21-24 years-olds. The difference was statistically significant at $\mathrm{x}^{2}=83.4, \mathrm{p}=0.000$

Table 1. Socio-demographic characteristics of sexually active respondents

\begin{tabular}{|c|c|c|c|c|}
\hline Characteristics & Students (\%) & Out-of-school (\%) & Total (\%) & $\mathrm{p}$-value \\
\hline \multicolumn{4}{|c|}{ Age(years) } & 0.000 \\
\hline $15-17$ & $128(42.7)$ & $103(34.3)$ & $231(38.5)$ & \\
\hline $18-20$ & $122(40.7)$ & $102(34.0)$ & $224(34.3)$ & \\
\hline $21-24$ & $50(16.7)$ & $95(31.7)$ & $145(24.2)$ & \\
\hline Mean \pm SD & $18.14 \pm 2.2$ & $\begin{array}{c}18.99 \pm 2.6 \\
5\end{array}$ & $18.57 \pm 2.47$ & \\
\hline Range & $15-24$ & $15-24$ & $15-24$ & \\
\hline \multicolumn{4}{|c|}{ Gender } & 0.297 \\
\hline Male & $195(65.0)$ & $208(69.3)$ & $403(67.2)$ & \\
\hline Female & $105(35.6)$ & $92(30.7)$ & $197(32.8)$ & \\
\hline \multicolumn{4}{|c|}{ Religion } & 0.620 \\
\hline Christianity & $151(50.3)$ & $155(51.7)$ & $306(51.0)$ & \\
\hline Islam & $139(46.3)$ & 131(43.7) & $270(45.0)$ & \\
\hline Traditional & $10(3.3)$ & $14(4.7)$ & $24(4.0)$ & \\
\hline \multicolumn{4}{|c|}{ Ethnicity } & 0.566 \\
\hline Yoruba & $213(71.0)$ & $215(71.7)$ & $428(71.3)$ & \\
\hline Hausa & $36(12.0)$ & $37(12.3)$ & $73(12.2)$ & \\
\hline Igbo & $49(16.3)$ & $48(16.0)$ & $97(16.2)$ & \\
\hline Others & $2(0.7)$ & $0(0.0)$ & $2(0.3)$ & \\
\hline \multicolumn{4}{|c|}{ Teenager } & 0.000 \\
\hline Teenagers & $229(76.3)$ & $182(60.7)$ & $411(68.5)$ & \\
\hline Not Teenagers & $71(23.7)$ & $118(39.3)$ & $189(31.5)$ & \\
\hline TOTAL & $300(100)$ & $300(100)$ & 600 & \\
\hline
\end{tabular}


Table 2. Sexual characteristics of In-school and out-of-school youths in Ekiti, Nigeria

\begin{tabular}{|c|c|c|c|c|c|}
\hline Ever Had Sex & Yes $(\%)$ & $\mathrm{No}(\%)$ & Total & $X^{2}$ & p-value \\
\hline In-School & $181(60.3)$ & $119(39.7)$ & 300 & 1.606 & 0.237 \\
\hline Out-of-School & $196(65.3)$ & $104(34.7)$ & 300 & & \\
\hline \multicolumn{4}{|c|}{ Gender: } & 0.103 & 0.408 \\
\hline Male & $255(63.3)$ & $148(36.7)$ & 403 & & \\
\hline Female & $122(61.9)$ & $75(38.1)$ & 197 & & \\
\hline \multicolumn{4}{|c|}{ Among In-School } & 0.112 & 0.805 \\
\hline Male (\%) & $119(61.0)$ & $76(39.0)$ & 195 & & \\
\hline Female (\%) & $62(59.0)$ & $43(41.0)$ & 105 & & \\
\hline \multicolumn{4}{|c|}{ Among out-of-school } & 0.001 & 0.999 \\
\hline Male (\%) & $136(65.4)$ & $72(34.6)$ & 208 & & \\
\hline Female $(\%)$ & $60(65.2)$ & $32(34.8)$ & 92 & & \\
\hline \multicolumn{4}{|c|}{ Age in group } & 83.40 & 0.000 \\
\hline $15-17$ & $98(42.4)$ & $133(57.6)$ & 231 & & \\
\hline $18-20$ & $151(67.4)$ & $73(32.6)$ & 224 & & \\
\hline $21-24$ & $128(88.3)$ & $17(11.7)$ & 145 & & \\
\hline TOTAL & $377(62.8)$ & $223(37.2)$ & 600 & & \\
\hline \multicolumn{5}{|c|}{ Age at $1^{\text {st }}$ Intercourse } & 0.002 \\
\hline $11-12$ & $55(30.4)$ & $55(28.1)$ & \multicolumn{2}{|c|}{$110(29.2)$} & \\
\hline $13-14$ & $106(58.6)$ & $92(46.9)$ & \multicolumn{2}{|c|}{$198(52.5)$} & \\
\hline After 14 years & $20(11.0)$ & $49(25.0)$ & \multicolumn{2}{|c|}{$69(18.3)$} & \\
\hline Mean \pm SD & $13.2 \pm 1.15$ & $13.6 \pm 1.9$ & \multicolumn{2}{|c|}{$13.4 \pm 1.4$} & \\
\hline Range & $11-17$ & $11-17$ & \multicolumn{2}{|c|}{$11-17$} & \\
\hline \multicolumn{6}{|c|}{ Lifetime sexual Partners $X^{2}=5.940, d f=2, p=0.115$} \\
\hline & 1 & 2 & \multicolumn{2}{|c|}{3 or More } & Total \\
\hline In-School (\%) & $115(63.5)$ & $51(28.2)$ & \multicolumn{2}{|c|}{$15(8.3)$} & 181 \\
\hline Out-of-school & $109(55.6)$ & $55(28.1)$ & \multicolumn{2}{|c|}{$32(16.3)$} & 196 \\
\hline Total (\%) & $224(59.4)$ & $106(28.1)$ & \multicolumn{2}{|c|}{$47(12.5)$} & 377 \\
\hline \multicolumn{6}{|c|}{ Sexual partners in the last 3 months $\mathrm{X}^{2}=7.621, \mathrm{df}=2, \mathrm{p}=0.022$} \\
\hline & 0 & 1 & \multicolumn{2}{|c|}{2 or more } & Total \\
\hline In-School & $82(45.3)$ & $88(48.6)$ & \multicolumn{2}{|c|}{$11(6.1)$} & 181 \\
\hline Out-of-school & $78(39.8)$ & $89(45.4)$ & \multicolumn{2}{|c|}{$29(14.8)$} & 196 \\
\hline Total (\%) & $160(42.4)$ & $177(46.9)$ & \multicolumn{2}{|c|}{$40(10.6)$} & 377 \\
\hline \multicolumn{6}{|c|}{ Ever had Sex with commercial sex work $\mathrm{x}^{2}=7.721, \mathrm{df}=1, \mathrm{p}=0.005$} \\
\hline & Yes(\%) & $\mathrm{No}(\%)$ & \multicolumn{2}{|c|}{ Total } & \\
\hline In-School & $26(14.4)$ & $154(85.6)$ & \multicolumn{2}{|c|}{$77(20.5)$} & \\
\hline Out-of-school & $51(26.0)$ & $145(74.0)$ & \multicolumn{2}{|c|}{$299(79.5)$} & \\
\hline Total & $180(47.9)$ & $196(52.1)$ & \multicolumn{2}{|c|}{376} & \\
\hline
\end{tabular}

One hundred and fifteen (63.5\%) of the sexually active in-school youths and 109 (55.6\%) of the sexually active out-of- school youths could recall having had sex with one lifetime partner as shown in Table 2. Only $66(22.0 \%)$ of the in-school youths reported to have slept with more than one sexual partners $(\mathrm{p}=0.115)$. Eighty two $(45.3 \%)$ in-school youths and 78(39.8\%) out-of-school youths claimed not to have had sex in the last three months compared with $88(48.6 \%)$ in-school youths and $89(45.4 \%)$ out-of-school youths who reported to have had sex with only one partner within same period $(\mathrm{p}=0.079)$. Twenty six $(14.4 \%)$ sexually active in-school youths and $51(26.0 \%)$ sexually active out-of-school youths reported having ever had sex with commercial sex workers.The difference was however significant $\left(\mathrm{x}^{2}=7.612, \mathrm{p}=0.005\right)$

\subsection{Use of Condom}

All the 377 respondents who claimed to have had sex before were further studied to know their extent of condom use. As shown in Table 3, only 54 (29.8\%) in-school youths reported that they or their partners ever used condom during sexual intercourse and $80(40.8 \%)$ of the out-of- school youths reported the use of condom during coitus. This difference was found to be significant ( $\mathrm{p}=0.031$ ). In all, $35.5 \%$ of the sexually active respondents ever used condom.

However, further analysis of those who claimed to have used condom shows that only $6(10.7 \%)$ of the in-school youths or their partners who claimed to have ever used condom actually used condom regularly while majority, 50 (89.3\%) used it occasionally. Among the out-of-school youths, a higher percentage, 14(20.6\%) used condom regularly and $54(79.4 \%)$ used it occasionally. Between group comparison showed that more out-of-school youths than the in-school youths used condoms regularly; the difference however was not significant $(\mathrm{p}=0.151)$.

Further analysis showed that 105 (38.5\%) male respondents reported that they used condom during sexual intercourse compared to 49 (50\%) females who reported that their male sexual partners used condom $(\mathrm{p}=0.568)$.

Various reasons were given by the respondents for using condom as shown in Table 3. Twenty seven (49.1\%) in-school youths and 33(51.60\%)

Out-of-school youths used condom for dual protection while $19(34.5 \%)$ student and 15 (23.4\%) out-of-school youth used condom during sexual intercourse to prevent sexual transmitted diseases while only 9 (16.4\%) in-school youths and $16(25.0 \%)$ out-of-school youths reported that they use condom during sexual intercourse to prevent pregnancy. The differences were however not significant $(\mathrm{p}=0.307)$. About half of all respondents who answered the question "why don't you use condom?" cited poor sexual satisfaction as reasons why they don't use condom while $72(40.4) \%$ of in-school youths said they did not use condom 
because their partners did not like it.

Among the in-school youths, religion $(\mathrm{p}=0.062)$ is the only variables found to be associated with use of condom; whilst age $(\mathrm{p}=0.024)$ and gender $(\mathrm{p}=0.008)$ are significantly associated to condom use among out-of-school youths as shown in Table 4. In whole condom use was associated with age $(p=0.017)$, being a teenager $(p=0.017)$, family type $(\mathrm{p}=0.031)$, marital status of respondents, parents $(\mathrm{p}=0.000)$ and also respondents' residential status $(p=0.012)$ The stepwise multivariate logistic regression revealed in Table 5 that Religion $(\mathrm{OR}=2.35$; $\mathrm{CI}: 1.21$ - 4.58), family type (OR: 2.40; CI: $1.21-4.74)$ and residential status (OR: 0.14; CI: $0.03-0.61$ for living with one parent versus living alone) are factors independently associated with condom use among the in-school youths as shown in Table 5. In-school youths practicing Islam religion are over two times more likely to use condom than their Christian counterparts. Also, age group (OR: 3.19, CI: $1.34-7.56$ ), gender and residential status are factors independently associated with condom use among out-of-school youths. Out-of-school youths aged 18-20 are about three times more likely to use condom than those aged 15-17 and the males among out-of-school youths are over three times more likely to use condom when compared with their female counterparts. When condom use among the whole respondents were considered, age group (OR: 2.45; CI: $1.39-4.34$ ), whether a teenager or not (OR: 1.67; CI: $1.09-2.55$ ), family type (OR: $1.92 ; \mathrm{CI} ; 1.24-2.98$ for monogamy versus polygamy) as well as residential status are associated independently to the practice. Studentship status was found to be significant at $10 \%$ significance level to condom use as the out-of-school youths were found to use condom about one and half times more likely than the in-school youths.

Table 3. Condom use among In-school and out-of-school youths in Ekiti, Nigeria

\begin{tabular}{|c|c|c|c|c|}
\hline Condom Use & In-School (\%) & Out-of-school \%) & Total & p-value \\
\hline Yes & $54(29.8)$ & $80(40.8)$ & $134(35.5)$ & \multirow{3}{*}{0.031} \\
\hline No & $127(70.2)$ & $116(59.2)$ & $243(64.5)$ & \\
\hline Total & $181(48.0)$ & $196(52.0)$ & 377 & \\
\hline Regularity of condom use & In-School (\%) & Out-of-school (\%) & Total & p-value \\
\hline Every time & $6(10.7)$ & $14(20.6)$ & $20(16.1)$ & \multirow{3}{*}{$\begin{array}{c}0.151 \\
104(83.9\end{array}$} \\
\hline Occasionally & $50(89.3)$ & $54(79.4)$ & 104(83.9) & \\
\hline Total & $56(45.2)$ & $68(54.8)$ & 124 & \\
\hline Reasons for use of condom & In-School (\%) & Out-of-school (\%) & Total $(\%)$ & p-value \\
\hline To prevent Pregnancy & $9(16.4)$ & $25(21.0)$ & $16(25.0)$ & \multirow{3}{*}{0.307} \\
\hline To prevent STDs & $19(34.5)$ & $15(23.4)$ & $34(28.6)$ & \\
\hline Dual protection & $27(49.1)$ & $33(51.6)$ & $60(50.4)$ & \\
\hline Total & $55(46.2)$ & $64(53.8)$ & 119 & p-value \\
\hline $\begin{array}{l}\text { Reasons for not using } \\
\text { condom }\end{array}$ & In-School (\%) & Out-of-school (\%) & Total $(\%)$ & \multirow{4}{*}{0.113} \\
\hline Partner's choice & $72(40.4)$ & $64(32.7)$ & $136(36.4)$ & \\
\hline Poor Pleasure & $86(48.3)$ & $97(49.5)$ & $183(48.9)$ & \\
\hline Don't Know Condom & $20(11.2)$ & $35(17.9)$ & $55(14.7)$ & \\
\hline
\end{tabular}


Table 4. Report of condom use among youths according to some selected characteristics

\begin{tabular}{|c|c|c|c|c|c|c|c|c|c|}
\hline & \multicolumn{3}{|c|}{ In-school Youths } & \multicolumn{3}{|c|}{ Out of school Youths } & \multicolumn{3}{|c|}{ Overall } \\
\hline Variables & $\mathrm{N}$ & $\mathrm{n}(\%)$ & p-value & $\mathrm{N}$ & $\mathrm{n}(\%)$ & p-value & $\mathrm{N}$ & $\mathrm{n}(\%)$ & p-value \\
\hline Age Group & & & 0.273 & & & $0.024 *$ & & & $0.017^{*}$ \\
\hline $15-17$ & 56 & $14(25.0)$ & & 42 & $11(26.2)$ & & 98 & $25(25.5)$ & \\
\hline $18-20$ & 84 & $30(35.7)$ & & 67 & $35(52.2)$ & & 151 & $65(43.0)$ & \\
\hline $21-24$ & 41 & $10(24.4)$ & & 87 & $34(39.1)$ & & 128 & $44(34.4)$ & \\
\hline Age at 1 st intercourse & & & 0.279 & & & 0.172 & & & 0.179 \\
\hline $11-12$ & 55 & $12(21.8)$ & & 55 & $23(41.8)$ & & 110 & $35(31.8)$ & \\
\hline $13-14$ & 106 & $36(34.0)$ & & 92 & $32(34.8)$ & & 198 & $68(34.3)$ & \\
\hline Above 14 & 20 & $6(30.0)$ & & 49 & $25(51.0)$ & & 69 & $31(44.9)$ & \\
\hline Teen or Not & & & 0.089 & & & 0.187 & & & $0.017 *$ \\
\hline Non Teenagers & 59 & $22(37.3)$ & & 109 & $49(45.0)$ & & 168 & $71(42.3)$ & \\
\hline Teenagers & 122 & $32(26.2)$ & & 87 & $31(35.6)$ & & 209 & $63(30.1)$ & \\
\hline Gender & & & 0.392 & & & $0.008^{*}$ & & & 0.088 \\
\hline Male & 119 & $33(27.7)$ & & 136 & $64(47.1)$ & & 255 & $97(38.0)$ & \\
\hline Female & 62 & 21(33.9) & & 60 & $16(26.7)$ & & 122 & $37(30.3)$ & \\
\hline Religion & & & 0.062 & & & 0.975 & & & 0.281 \\
\hline Christianity & 95 & $22(23.2)$ & & 112 & $45(40.2)$ & & 207 & $67(32.4)$ & \\
\hline Islam & 81 & $29(35.8)$ & & 79 & $33(41.8)$ & & 160 & $62(38.8)$ & \\
\hline Traditional & 5 & $3(60.0)$ & & 5 & $2(40.0)$ & & 10 & $50(50.0)$ & \\
\hline Tribe & & & 0.156 & & & 0.916 & & & 0.524 \\
\hline Yoruba & 130 & $40(30.8)$ & & 140 & $58(41.4)$ & & 270 & $98(36.3)$ & \\
\hline Hausa & 22 & $3(13.6)$ & & 24 & $10(41.7)$ & & 46 & $13(28.3)$ & \\
\hline Igbo & 29 & $11(37.9)$ & & 32 & $12(37.5)$ & & 61 & $23(37.7)$ & \\
\hline Family type & & & 0.111 & & & 0.093 & & & $0.031 *$ \\
\hline Polygamous & 101 & $35(34.7)$ & & 101 & $47(46.5)$ & & 202 & $82(40.6)$ & \\
\hline Monogamous & 80 & $19(23.8)$ & & 95 & $33(34.7)$ & & 175 & $52(29.7)$ & \\
\hline Years of Education & & & 0.479 & & & 0.279 & & & 0.299 \\
\hline Under 10 years & 36 & $9(25.0)$ & & 47 & $16(34.0)$ & & 83 & $25(30.1)$ & \\
\hline !0 years \& Above & 145 & $45(31.0)$ & & 149 & $64(43.0)$ & & 294 & 109(37.1) & \\
\hline Parent Marital Status & & & 0.180 & & & 0.292 & & & 0.063 \\
\hline Together & 112 & $39(34.8)$ & & 126 & $54(42.9)$ & & 238 & 93(39.1) & \\
\hline Separately & 28 & $4(14.3)$ & & 32 & $9(28.1)$ & & 60 & $13(21.7)$ & \\
\hline Divorced & 24 & $7(29.2)$ & & 21 & $11(52.4)$ & & 45 & $18(40.0)$ & \\
\hline One/Both parent dead & 17 & $4(23.5)$ & & 17 & $6(35.3)$ & & 34 & $10(29.4)$ & \\
\hline Residential Status & & & $0.011 *$ & & & 0.105 & & & $0.012 *$ \\
\hline With both Parent & 110 & $41(37.3)$ & & 115 & $48(41.7)$ & & 225 & $89(39.6)$ & \\
\hline With one Parent & 51 & $6(11.8)$ & & 53 & $19(35.8)$ & & 104 & $25(24.0)$ & \\
\hline With Guardian & 9 & $3(33.3)$ & & 11 & $8(72.7)$ & & 20 & $11(55.0)$ & \\
\hline Alone & 11 & $4(36.4)$ & & 17 & $5(29.4)$ & & 28 & $9(32.1)$ & \\
\hline Parental Control & & & 0.533 & & & 0.628 & & & 0.499 \\
\hline None & 35 & $11(31.4)$ & & 40 & $14(35.0)$ & & 75 & $25(33.3)$ & \\
\hline Little & 68 & $17(25.0)$ & & 72 & $29(40.3)$ & & 140 & $46(32.9)$ & \\
\hline Much & 78 & $26(33.3)$ & & 84 & $37(44.0)$ & & 162 & $63(38.9)$ & \\
\hline $15-17$ & 56 & $14(25.0)$ & & 42 & $11(26.2)$ & & 98 & $25(25.5)$ & \\
\hline & & & & *Stat & 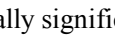 & $\mathrm{p}<0.0$ & & & \\
\hline
\end{tabular}


Table 5. Logistic Regression of condom use among youths on some selected characteristics

\begin{tabular}{|c|c|c|c|c|c|c|}
\hline \multirow[b]{2}{*}{ Variables } & \multicolumn{2}{|c|}{ In-school Youths } & \multicolumn{2}{|c|}{ Out of school Youths } & \multicolumn{2}{|c|}{ Overall } \\
\hline & $\operatorname{AOR}(95 \% \mathrm{CI})$ & $\mathrm{p}$-value & $\operatorname{AOR}(95 \% \mathrm{CI})$ & p-value & $\operatorname{AOR}(95 \% \mathrm{CI})$ & $\mathrm{p}$-value \\
\hline \multicolumn{7}{|l|}{ In or Out of school } \\
\hline In-school & - & - & - & - & 1.00 Reference & \\
\hline Out-of-school & - & - & - & - & $1.52(0.99-0.33)$ & 0.057 \\
\hline \multicolumn{7}{|l|}{ Age Group } \\
\hline $15-17$ & $0.84(0.33-2.14)$ & 0.721 & 1.00 Reference & & 1.00 Reference & \\
\hline $18-20$ & $1.66(0.73-3.77)$ & 0.228 & $3.19(1.34-7.56)$ & $0.008^{*}$ & $2.45(1.39-4.34)$ & $0.02 *$ \\
\hline $21-24$ & 1.00 Reference & & $1.93(0.84-4.44)$ & 0.124 & $1.70(0.94-3.07)$ & 0.08 \\
\hline \multicolumn{7}{|l|}{ Teen or Not } \\
\hline Non Teenagers & $1.55(0.80-3.00)$ & & $1.55(0.86-2.79)$ & 0.114 & $1.67(1.09-2.55)$ & $0.02 *$ \\
\hline Teenagers & 1.00 Reference & & 1.00 Reference & & 1.00 Reference & \\
\hline \multicolumn{7}{|l|}{ Gender } \\
\hline Male & 1.00 Reference & & $2.31(1.19-4.51)$ & $0.014 *$ & $1.42(0.89-2.25)$ & 0.142 \\
\hline Female & $1.24(0.64-2.39)$ & 0.531 & 1.00 Reference & & 1.00 Reference & \\
\hline \multicolumn{7}{|l|}{ Religion } \\
\hline Christianity & 1.00 Reference & & 1.00 Reference & & 1.00 Reference & \\
\hline Islam & $2.35(1.21-4.58)$ & $0.012 *$ & $1.02(0.57-1.84)$ & 0.947 & $1.43(0.93-2.21)$ & 0.105 \\
\hline Traditional & $5.40(0.84-34.57)$ & 0.075 & $0.49(0.05-4.85)$ & 0.561 & $1.70(0.44-6.54)$ & 0.441 \\
\hline \multicolumn{7}{|l|}{ Family type } \\
\hline Polygamous & $2.40(1.21-4.74)$ & $0.012 *$ & $1.71(0.96-3.07)$ & 0.067 & $1.92(1.24-2.98)$ & $0.003^{*}$ \\
\hline Monogamous & 1.00 Reference & & 1.00 Reference & & 1.00 Reference & \\
\hline \multicolumn{7}{|l|}{ Residential Status } \\
\hline With both Parent & $0.72(0.21-2.52)$ & 0.611 & $1.71(0.56-5.18)$ & 0.343 & $0.45(0.26-0.77)$ & $0.003 *$ \\
\hline With one Parent & $0.14(0.03-0.61)$ & $0.009 *$ & $1.27(0.39-4.17)$ & 0.693 & $2.28(0.90-5.81)$ & 0.083 \\
\hline With Guardian & $0.96(0.16-5.64)$ & 0.964 & $6.40(1.18-34.61)$ & $0.031^{*}$ & $0.85(0.37-1.92)$ & 0.69 \\
\hline Alone & 1.00 Reference & & 1.00 Reference & & 1.00 Reference & \\
\hline
\end{tabular}

\section{Discussion}

Globally, promoting the reproductive health of youths aged $15-24$ years is necessary for growth and future development. Youths aged 15-24 years represent a unique period in the human life cycle. This is because they are no longer children and not yet adults and as a result they make significant choices about their health and develop attitudes and health practices that affect their current safety and well-being as well as influence their risk for future serious chronic disease.

The overall goal of the National policy on Population for Sustainable Development is to improve quality of life and standard of living for the Nigeria population[7]. This is achievable through improvement in the reproductive health of all Nigerians at every stage of the life cycle and acceleration of a strong and immediate response to the HIV/AIDS pandemic and other related infectious diseases. As part of the efforts to achieve these aims, examining condom use among youths aged $15-24$ will be of the most effective strategies for combating teenage and unwanted pregnancy and prevention of sexually transmitted diseases including HIV/AIDS, hence this study.

Data analysis showed that, fewer (although insignificant $p=0.237)$ in-school youths $(60.3 \%)$ than out-of-school youths $(65.3 \%)$ reported having had sexual intercourse. This finding is in agreement with other studies in Nigeria that report higher rates of sexual activity among the out of school youths[17, 21]. Overall, more males $(63.3 \%)$ had had sex than females $(61.9 \%)$. However, similar proportion of male and female in-school youths had had sexual intercourse at the time of this study. Similarly, about two third each among the two categories of male out-of-school youths female out-of-school youths had ever had sexual intercourse. These are corroborated by similar studies in the western[21] and north central[22] regions of Nigeria, where it was reported that more males than females had ever had sexual intercourse. Gender gap in terms of assumed self reliance and family freedom by male youths relative to females can be explanatory factor in this regard. In Africa setting, male child often enjoy more freedom than their female counterparts on issues involving their personal lives. 
Generally, the proportion of youths who had sexual intercourse was found to increase gradually with age as shown in Table 2, it is not really surprising that the proportion of young people who ever had sexual intercourse increases significantly with age in the 15-24 year olds. We found that the proportion of youths who had ever had sexual intercourse increased from $42.3 \%$ among the $15-17$ year-olds to $66.7 \%$ among the $18-20$ year-olds and $88.1 \%$ among 21-24 year old. Two studies in Nigeria[22, 23] have indicated that sexual activity increases with increasing age, with the proportion of sexually active students increasing from $26 \%$ of $14-24$ years to $54-55 \%$ among 18 to 19 year olds in a study involving 2,640 students[23]. Similarly, the 2008 Demographic and Health Survey (DHS)[8] of adolescents in Nigeria reported that the percentage of unmarried females who have had sex increases from $26 \%$ among the $15-19$ year olds to $66 \%$ among the $20-24$ year olds.

Further analysis also revealed that more out-of-school than in-school youths reported having had sexual intercourse with more than one (two or more) lifetime sexual partner. The proportion of youths who reported that they have multiple sexual partners are slightly higher than the findings of $[25]$ in Ibadan, an urban setting, who reported that $28 \%$ of the in-school youths studied had more than two sexual partners. Several studies have also documented high levels of sex with multiple partners in various parts of Nigeria and other African countries. In Rural Tanzania, eleven boys reported having at least 4 partners[25], and a boy reported a total of 9 casual partners. It is possible that the boys didn't use condom with any of the partners. In Dar-Es-salaam, Tanzania, $49.5 \%$ of sexually active young boys reported more than five lifetime partners[13] compared with $14.1 \%$ of females.

It is worthwhile to know that a lower proportion (14.4\%) of the sexually active in-school youths and $26.0 \%$ of out-of-school youths reported sexual contact with commercial sex workers.

Information was also sought on use of condoms among those who had ever had sex. This is to determine the proportion of the set of youths who were engaging in high risk sex. Approximately $30 \%$ of the sexually active in-school youths and $40.8 \%$ of sexually active out-of-school youths reported that they ever used condom during sexual intercourse. These figures are quite low, bearing in mind that $60 \%$ of the respondents are sexually active. In addition, about half, $49.1 \%$ of the in-school youths who use condom and $51.6 \%$ of the out-of-school used the condom for dual protection. Although condoms have many advantages, the two well known of these advantages are their efficacy in protecting consistent users from sexually transmitted disease, including HIV/AIDS, and unwanted pregnancy.

There was a significant disparity between condom knowledge and the rate of use with regard to the usefulness of condom in prevention against HIV infection among in-school youths and out-of-school youths. Although 34.5\% sexually active in-school youths and $23.4 \%$ sexually active out-of-school believed that HIV infection could be prevented with the regular use of condom, only $10.7 \%$ of the sexually active in-school youths and $20.6 \%$ of the out-of-school youths used the condom regularly i.e. with every sexual act. This is a source of concern now that the prevalence of HIV/AIDS is increasing at an alarming rate in Nigeria and there is virtually little or no means of ascertaining if individuals who have not undergone HIV test are already HIV infected or not. Therefore, availability of HIV counselling and testing programmes in the study area will improve the use of condom during sexual intercourse among youths.

The stepwise logistic regression showed that out-of-school youths are more likely to use condom than the in-school youths. A possible explanation is that fewer in-school youths engage in sex with multiple partners. Also, most of the out-of-school youths engage in one trade or the other which could earn them income, thus enhancing their condom purchasing power compared to the in-school youths. The out of school youths would have better access to condom as they are no longer under strict regulations enforced in school environments. This finding could also be credited to the fact that more out-of-school-youths had had sexual contact with commercial sex workers thereby prompting them to use condom more often. Although condom is generally assumed to be affordable (less than $\$ 0.25$ ) and easily available in shops and chemists across Nigeria, intending users may have problems obtaining it as people often look down on condom buyers especially youths as being irresponsible.

Liberalization of condom in terms of free distribution to youths in the study area can tremendously fill this gap. However, programs for total abstinence from sex among these unmarried youths could be a better solution to unsafe sexual attitudes. There is no significant association between years of education and condom use among the two categories; this could be attributed to long years of education before the out-of-school youths dropped out (Table 4) which explained why condom use is more prevalent among the dropped outs.

The identified underlying factors affecting condom use among the study population are family types, religion, residential status, age, gender. However, different characteristics were found to have influenced condom use among the in-school youths and the out of school youths. While family types, religion and residential status were found to be significantly associated with condom use among in-school youths; age, gender, family types, and residential status influence the usage among out-of-school youths. This finding shows similar result with[26] where the major predictors of condom use were: type of school, location of the school, sex, age, living arrangement, religion and having a boy/girl friend.

\section{Conclusions}

The prevalence of condom use among the youths in the 
study area was low and was higher among out-of-school than in-school youths. Act of having sex with more than one sexual partner and with commercial sex workers was not prominent among out-of-school than in-school youths. Therefore, free access to condom and early sexual education will make a difference in terms of condom use. However, total abstinence should be encouraged among all youths. Government and Non-governmental agencies should see this as a challenge. Prevalence of usage of condom during different types of sexual acts should be explored in future studies

\section{REFERENCRES}

[1] The World Bank's Global HIV/AIDS Program of action, (2005)

[2] Richard Hunt (2008) HIV/AIDS Statistics; http://pathmicro.med.sc.edu/lecture/hiv5.htm; Retrieved February 22, 2011

[3] UNAIDS (2010). Available at http://www.unaids.org/docum ents/20101123_GlobalReport_em.pdf Accessed 21 February 2011).

[4] Ekweozor C.C, Olaleye O.D, Tomori O. Saliu I, Essien E.M, Bakare R.A, Oni A.A, Oyewo O.O, Okesola O.A and Onyemenen T.N (1995). Clinico-epidemiological patterns of HIV infection in STD patients in Ibadan. African Journal of Medicine and Medical Science; 24: 321-27

[5] McCauley A.P and Salter C (1995). Meeting the needs of young adults. Population Reports. Series J, Number 41 .

[6] Association for Reproductive and family Health (2000). The baseline survey for the Expanded Life Planning Education. ELPE Serie L, 2000.

[7] National Population commission(2008)'; Reports on 2008 population census in Nigeria

[8] Connel J.P. Context (1990), Self and action: a motivational analysis of self system processes across the life span. In: Chichetti D. and Beeghy M. (Eds). The self in transition: infancy to childhood. Chicago. University of Chicago Press, 1990, pg 61-79

[9] Orubuloye I.O, Caldwell J. and Caldwell P (1991). Sexual networking in the Ekiti District of Nigeria. Stud Fam plan; 22:61-73

[10] Lema V.M (1990). Sexual behaviour, contraceptive practice and knowledge of reproductive biology among adolescent secondary school girls in Nairobi, Kenya. East Afr Med J; 67(2): 86-94.

[11] Kiragu K. (1991). Factors associated with sexual and contraceptive behaviour among school adolescents in Kenya: The 1989 Nakiru District Adolesecent Fertility survey, final report. John Hopkins University School of Hygiene and Bublic Health. 38p.

[12] Kobayahsi M, Murakami Y and Yoshidome (2001). A knowledge, behaviour and attitude towards sex among adolescent student at a junior/high school in Cote d'Ivoire.[Nippon koshu eisei zasshi] Japanese journal of public health 2001;48(2):132-41

[13] Mwakagile D, Mmari E, Makwaya C, Mbwana J, Biberfeld G, Mhalu F and Sanstrom E (2001). Sexual behaviour among youths at high risk for HIV-I infection in Dar-Es-Salaam, Tanzania. Sex Transm Infect; 774 (4):255-9

[14] Mosher WD and Jones J (2010), Use of contraception in the United States: 1982-2008, Vital and Health Statistics, Series 23, No. 29

[15] Akinyemi, O. J., Olutosin A. Awolude, Isaac F. Adewole, Phyllis J. Kanki (2010); Condom use among antiretroviral therapy patients in Ibadan, Nigeria; Journal of Infect Dev Countries; 4(8):495-502

[16] Jinadu MK (2002); Sexual behaviour and condom use among adolescent in Ile-Ife, Nigeria. Int Conf AIDS. 1992 Jul 19-24; 8: $\mathrm{C} 360$

[17] Sunmola A. M., Benjamin O. Olley and Grace E. Oso (2006); Predictors of condom use among sexually active persons involved in compulsory national service in Ibadan, Nigeria. Oxford Journals Medicine Health Education Research Volume22, Issue 4, Pp. 459-472

[18] Allen S, Meinzen-Derr J, Kautzman M, et al. (2003) Sexual behavior of HIV discordant couples after HIV counseling and testing. AIDS 17: 733-740

[19] Wawer MJ, Gray RH, Sewankambo NK, et al. (2005) Rates of HIV-1 transmission per coital act, by stage of HIV-1 infection, in Rakai, Uganda. J Infect Dis 191: 1403-1409

[20] Feldblum PJ, Lie C-C, Weaver MA, et al. (2010) Baseline factors associated with incident HIV and STI in four microbicide trials . Sex Transm Dis in press:DOI: 10.1097/ OLQ.0b013e3181e15fob

[21] Ajuwon A J, Olley B.O, Akin-Jimoh I, and Akintola O, (2001). Experience of sexual coercion among adolescents in Ibadan, Nigeria. Afr J. Reprod Health; 5(3): 120-131

[22] Slap GB, Lot L, Huang B, Daniyan CA, Zink TM, Succop PA. (2003) Sexual behavior adolescents in Nigeria: cross sectional survey of secondary school students. Brit Med J. 2003;326:1-6. doi: 10.1136/bmj.326.7379.15.

[23] Amazigo U, Silva N, Kaufman J, Obikeze D.S (1997) sexual activity, contraceptive knowledge and use among in-school adolesecents in Nigeria. Int Fam Plann Perspect; 23(1): 28-33

[24] Olaseha I.O and Alao A (1991). Knowledge, attitude and risk behaviors of adolescent students: towards AIDS prevention and control in Ibadan City, Oyo State, Nigeria. Nigeria School Health Journal; 7(2) 127-133

[25] Nnko S, Chiduo B, Mwaluko G and Urassa M (2001). Pre-marital sexual behaviour among out-of-school adolescen ts: motives, patterns and meaning attributed to sexual partnership in rural Tanzania. Afr J Reprod Health; \%(3): $162-174$.

[26] Ajuwon A J , Olaleye A, Faromoju B and Ladipo O (2006), sexual behavior and experience of sexual coercion among secondary school students in three states in North Eastern Nigeria BMC Public Health 2006, 6:310 